\title{
Development of mouse ovarian follicles from primary to preovulatory stages in vitro
}

\author{
R. Qvist*, L. F. Blackwell*†, H. Bourne* and J. B. Brown* \\ * Department of Obstetrics \& Gynaecology, University of Melbourne, Parkville, Victoria 3052, \\ Australia; and $\dagger$ Department of Chemistry and Biochemistry, Massey University, Palmerston North, \\ New Zealand
}

\begin{abstract}
Summary. An in-vitro culture system was developed in which primary mouse follicles from 12-16-day-old mice grew to the preovulatory stage. The important determinants of growth in culture were the inclusion of stroma with the primary follicles, the age of the mouse, the presence of FSH and LH, the use of culture dishes with a hydrophobic membrane and the use of post-menopausal human serum to supply growth factors. During culture the pieces of ovarian tissue containing the primary follicles coalesced to form characteristic spherical clusters. The cultured follicles appeared to be normal as determined by the appearance and organization of the granulosa cells, the appearance of the antrum and the accompanying steroidogenesis, but the ova had not resumed meiosis. The results show that the growth of mouse follicles starting from the primary stage is critically dependent on adequate concentrations of FSH.
\end{abstract}

Keywords: FSH; mouse; culture; follicle; in vitro

\section{Introduction}

An in-vitro model which is free from normal feed-back control is required to test the hypothesis that follicle-stimulating hormone (FSH) acts on ovarian follicles at a series of threshold levels (Brown, 1978). Furthermore, the ability to culture ovarian follicles from the abundant primary stage through to ovulation followed by fertilization would have important applications in the study of ovarian physiology, in animal breeding and in human in-vitro fertilization programmes. We report here a system by which primary mouse follicles surrounded by stroma can be grown reproducibly through to the preovulatory stage with apparently normal granulosa cell organization and biochemical responses. In developing the system it was considered (i) that human FSH and luteinizing hormone (LH) would be appropriate for use in the mouse since mice are the most commonly used animal for the bioassay of human gonadotrophins, (ii) that human serum would contain all the necessary growth factors and (iii) that fetal calf serum, which is a commonly used supplement in tissue culture, would be inappropriate because of its hormone content.

\section{Materials and Methods}

Ovaries were obtained from BALB/c strain mice. The animals were killed by cervical dislocation and the ovaries were removed aseptically. Human pituitary FSH was obtained initially from Dr A. F. Parlow (Pituitary Hormone and Antisera Center, Harbor UCLA Medical Center, CA, USA): it was dissolved in buffer at a concentration of 900 i.u./ml as determined by radioimmunoassay (RIA) (Preparation A). Latterly, the FSH was obtained from Sigma Chemical Company (St Louis, MO, USA) and had a stated concentration of 6000 i.u./mg measured against IRP 60/104 by RIA (Preparation B). The source of FSH used in each study is indicated.

The basic culture medium was McCoy's 5A modified medium (Flow Laboratories, Melbourne, Australia) containing human serum and sterilized by filtration. Petriperm dishes were obtained from W. C. Heraeus GmbH 
(Hanau, West Germany) and millicell culture dishes were obtained from Millipore (Sydney, Australia). RIA kits for the measurement of oestradiol and progesterone were obtained from Biomediq (Melbourne, Australia).

Classification of follicles. The early stages of follicular development were classified according to the criteria of Mandl \& Zuckermann (1951) in which the number of granulosa cell layers and morphological appearance are the determining features. The antral stages were classified according to Pedersen \& Peters (1968) and Peters (1969). The following combined classification has been used in this study. Primordial follicles (Stage I) had a single layer of squamous cells around the ovum; primary follicles (Stages II and III) had 1 or 2 granulosa cell layers; Stage IV follicles had 3 layers of granulosa cells; Stage V follicles had > 3 layers of granulosa cells but no antrum; Stage VI follicles had early antral development; Stage VII follicles had full antral development and preovulatory follicles (Stage VIII) had fully developed cumulus around the ovum. Atresia was recognized by abnormal histology and by declining steroidal production. Atretic human follicles contain very little oestradiol in follicular fluid and only a low enzymic ability to synthesize oestradiol in response to FSH (McNatty, 1981). Falling oestradiol concentrations in culture fluid therefore represent a sensitive biochemical test for atresia.

Isolation of primary follicles. The primary follicles were teased from the ovarian mass under a dissecting microscope using very fine needles to give small pieces of ovarian tissue containing $\downarrow$ or 2 intact primary follicles with some stroma attached and without damage to the membrane or to the granulosa cells (see Figs la \& $1 \mathrm{~b}$, for typical examples). This method gave starting material for culture which was essentially homogeneous and contained only Stage I-III follicles. For the cultures, tissue containing primary follicles was obtained from several ovaries, pooled and then 3 or 4 pieces (similar to Fig. la) were distributed between incubation vessels to give a total of 4-8 primary follicles. Pieces of starting material for histological examination were chosen at random.
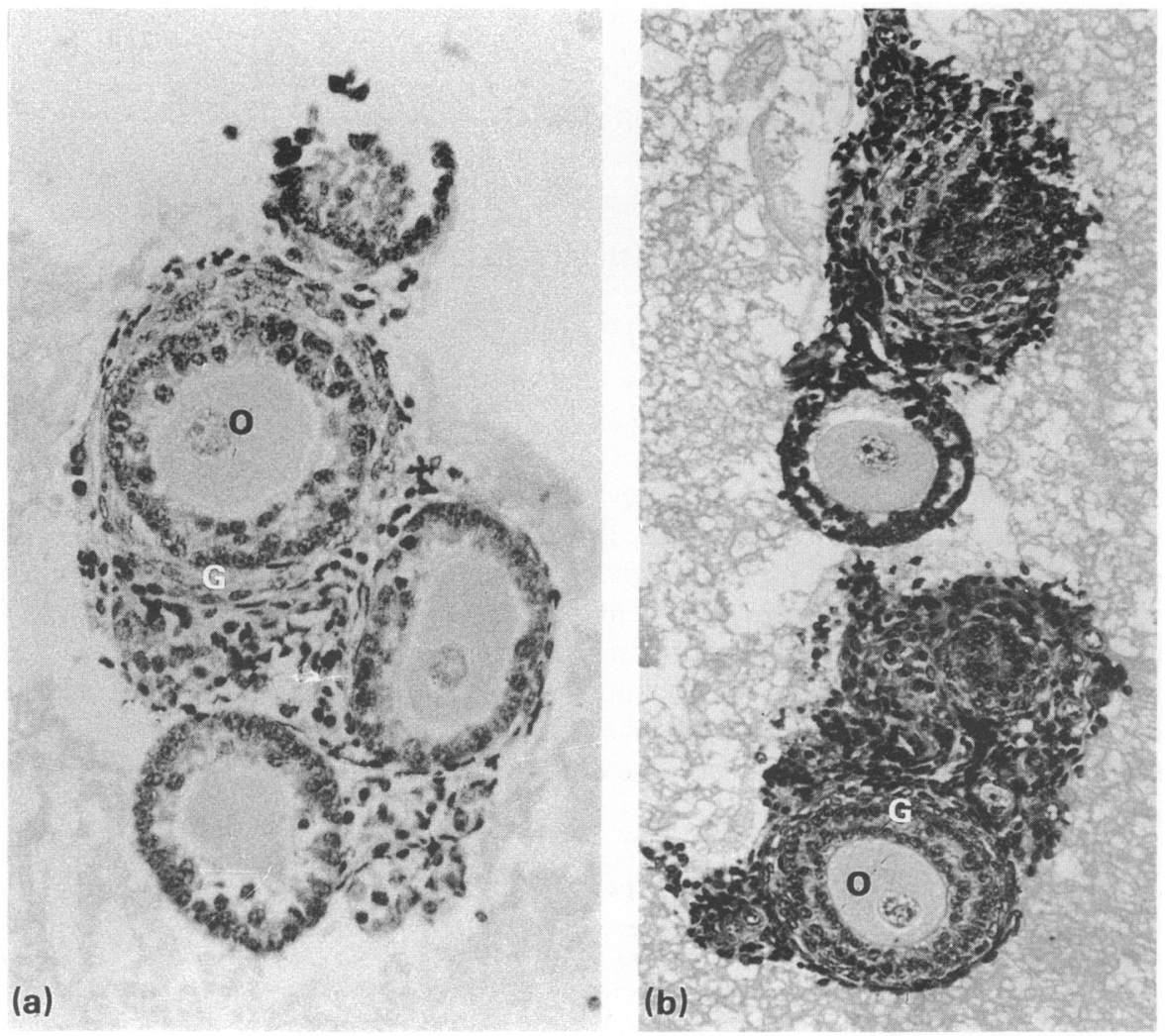

Fig. 1. Examples of primary follicles for in-vitro culture obtained from ovaries of mice aged 16-20 days. Only primary follicles are evident in the small pieces of tissue. The oocytes $(\mathrm{O})$ are shown surrounded by 1 or 2 layers of granulosa cells. (a) Ovarian tissue containing 3 primary follicles connected by stroma, $\times 248$. (b) Two sections containing single primary follicles, $\times 248$. 
Histology. The follicle clusters which formed after culture by coalescence of the original pieces of ovarian tissue (as in Figs $2 a$ \& 2b, for example) were aspirated in a drop of culture medium and transferred to a microfuge tube containing solidified agar. Bouin's aqueous fixative was layered on top of the culture medium. This formed a fine precipitate by coagulating the protein. After standing for $1 \mathrm{~h}$, the tube was centrifuged and the excess Bouin's solution was carefully decanted. Another layer of agar was carefully added and allowed to solidify with the ovarian tissue sandwiched between the two agar layers. The agar plug was removed from the tube and the whole was dehydrated and embedded in paraffin wax in the usual manner. Serial $5 \mu \mathrm{m}$ sections were cut through the sandwiched tissue layer and stained with haematoxylin and eosin. Since 34 follicles usually coalesced during culture (Figs $2 \mathrm{a} \& 2 \mathrm{~b}$, for example) the stage of development reached in each experiment was judged by the appearance of the most advanced follicle. The serial sections were examined to find the one showing the largest follicular diameter and also including the ovum. All measurements of granulosa cell layers, follicle diameters, appearance of the ovum and general histological comments refer to this section. Adjacent sections were examined to check that they were consistent with the main section and to eliminate any possibility of artefact. The photographs provided are representative of each type of experiment.
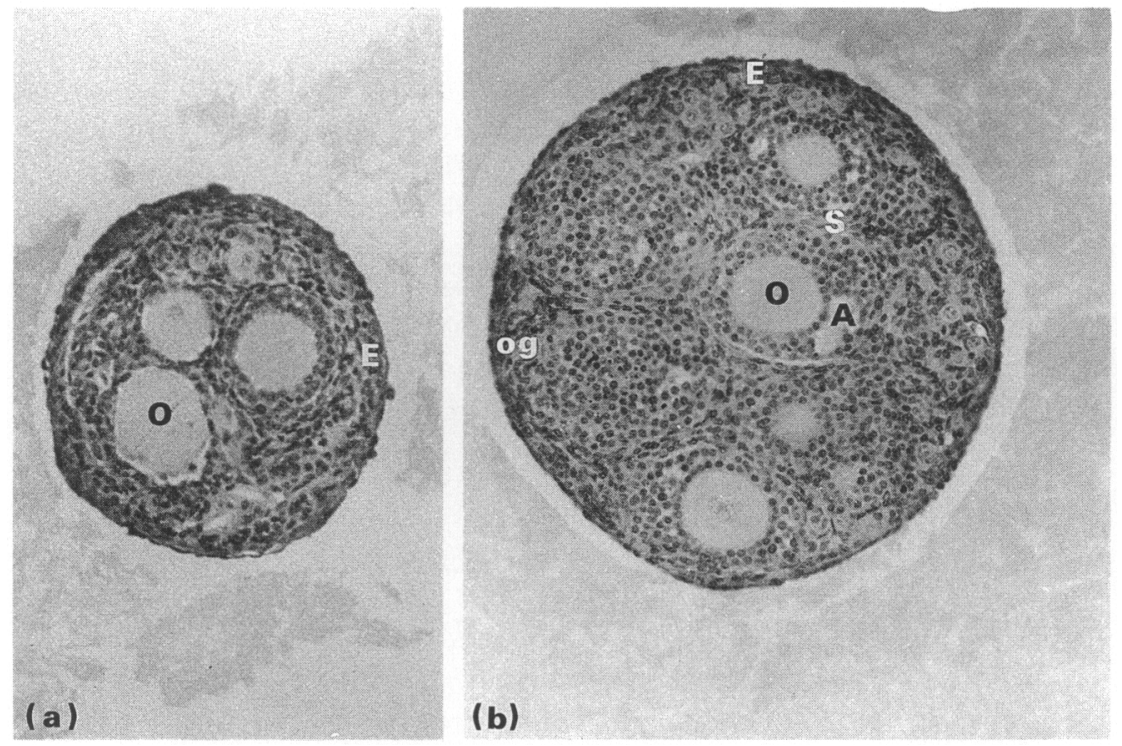

Fig. 2. Effect of children's serum on the stage of development reached by primary follicles ( $\times 90$ ). (a) Example of 3 primary follicles plus primordial follicles visible after growth for 10 days in the presence of endogenous FSH (0.5i.u./1) and LH (1.2i.u./1). $\mathrm{O}=$ oocyte; $\mathrm{E}=$ external cell layer. (b) Example of cluster after 12 days in 50\% children's serum supplemented with 690 i.u. $\mathrm{FSH} / \mathrm{l}$ showing 3 follicles with ova. $\mathrm{O}=$ oocyte; $\mathrm{A}=$ antrum; $\mathrm{S}=$ stromal cells; $\mathrm{E}=$ external cell layer.

Radioimmunoassays of oestradiol, progesterone, FSH and LH. Endogenous concentrations of FSH and LH in the serum of children, cyclic women and post-menopausal women were determined by RIAs. Iodinated tracers (FSD2 and LHD2) were from Diagnostic Products Corporation and obtained from Biomediq (Melbourne, Australia) and the antibodies were raised in rabbits and provided by Dr A. F. Parlow. The bound label was separated by goat antirabbit serum (Silenus, Melbourne, Australia) in buffers containing polyethylene glycol. The assays were standardized against the WHO first international reference preparations of FSH (78/549) and LH (68/40). The sensitivities were 0.4 i.u./l for FSH and 0.8 i.u./1 for LH with inter-assay and intra-assay coefficients of variation of $10 \%$ and $4.9 \%$ for FSH and $10 \%$ and $3.1 \%$ for $\mathrm{LH}$. Oestradiol and progesterone in the spent culture medium (containing $50 \%$ serum) were measured with RIA kits obtained from Diagnostic Products Corporation (Los Angeles, CA, USA) as instructed by the manufacturers. The sensitivity of the oestradiol assay was $8 \mathrm{pg} / \mathrm{ml}(0.03 \mathrm{nM})$ and the major cross-reacting steroids were oestradiol-3-glucuronide $(0 \cdot 7 \%)$, oestriol $(0 \cdot 3 \%)$ and oestrone $(1 \cdot 1 \%)$. The inter- and intra-assay coefficients of variation were $6.3 \%$ and $5.1 \%$ respectively. For the progesterone assay the stated sensitivity was $50 \mathrm{pg} / \mathrm{ml}(0.16 \mathrm{nM})$ and the major cross-reacting steroids were $17 \alpha$-hydroxyprogesterone $(0.3 \%), 5 \alpha$-pregnan-3,20dione $(0.8 \%)$ and $5 \beta$-pregnan-3,20-dione (1.3\%). The inter- and intra-assay coefficients of variation were $7.8 \%$ and $7 \cdot 2 \%$ respectively. 


\section{Results}

\section{Culture dishes}

Ordered proliferation of the granulosa cells (as distinct from mere spreading) was used as the general criterion to indicate suitable conditions. This was first achieved when primary follicles (similar to Fig. 1a) with adhering stroma were cultured in Petriperm dishes. The Petriperm dishes $(5 \mathrm{~cm}$ diameter) possessed a hydrophobic membrane which prevented adhesion of the primary follicles and also allowed ready diffusion of gases. With a fluid volume of $2.5 \mathrm{ml}$ the primary follicles were just covered by the culture medium as recommended by Neal \& Baker (1975). Other methods of follicle preparation (Soleto \& Brauer, 1975; Roy \& Greenwald, 1985) and utilization of conventional culture dishes coated with $1 \%$ agarose were unsuccessful.

\section{Supplements}

Growth of primary follicles at $37^{\circ} \mathrm{C}$ was consistently achieved only when the culture medium ( $\mathrm{pH} 7 \cdot 4$ ) was supplemented with $50 \%$ post-menopausal serum $(24-53$ i.u. FSH/1; 29-46 i.u. LH/1) and with up to 690 i.u. FSH/1 (Preparation A) (Ryle, 1969), provided that the mice were $>8$ days of age (see Figs 3c \& 3d, for example, as described below) and Petriperm dishes were used. Development of the follicles also occurred in lower concentrations of post-menopausal serum but not to the same extent. No growth of the follicles (Fig. 2a) was observed in children's serum (0.5 i.u. FSH/1, $1 \cdot 2$ i.u. $\mathrm{LH} / \mathrm{l})$ or in serum from ovulating women on Days $5-6$ of their cycle $(1 \cdot 2-6 \cdot 3$ i.u. FSH/l, 3-8 i.u. LH/1) although the follicles did not deteriorate over 10-15 days. Changing the culture medium every $48 \mathrm{~h}$ proved to be sufficient for maintaining growth.

\section{Oxygen concentration}

Increasing the oxygen concentration above $40 \%$ caused more rapid proliferation of the granulosa cells, but also caused rapid disintegration of the ovum and eventual necrosis of the granulosa cells as was noted by Brossemer \& Rutter (1961). Therefore, cultures were carried out using an atmosphere of $5 \% \mathrm{CO}_{2}$ and air saturated with water. Gentle agitation or using the rolling culture method of New et al. (1973) did not improve the results.

\section{Age of the mice}

Primary follicles (similar to those in Fig. 1a) isolated from 5-, 8-, 12- and 16-day-old mice were cultured in Petriperm dishes for 13 days in a medium containing 50\% post-menopausal serum supplemented with FSH (Preparation A) to give a total concentration of 690 i.u. FSH/l and 17 i.u. LH/1. Oestradiol was measured in the 48-h changes of culture medium. The starting primary follicles were morphologically similar irrespective of the age of the mouse. Primary follicles from the 5-day-old mice did not progress in culture beyond 2 layers of granulosa cells and the contained ovum showed no development (Fig. 3a). The most notable feature of the material after culture (initially torn pieces of tissue, as in Figs la \& 1 b) was the coalescence of the tissue containing the primary follicles into distinctive spheres containing up to 4 clearly developed follicles surrounded by a well defined layer of cells (as in Figs $3 a-3 d$ ). This was a consistent phenomenon for all cultures regardless of whether growth of the primary follicles occurred.

Primary follicles from mice older than 5 days developed as follows; 8-day-old mice, some follicles developed to Stage V (Fig. 3b); 12-day-old mice, some follicles to Stage V with many layers of granulosa cells (Fig. 3c); 16-day-old mice, all follicles developed, some follicles to Stage VII with a large antrum (as in Fig. 3d) and others to Stage V. The ova appeared healthy but thecal cell proliferation was not obvious. In each case the sections also included follicles which had developed to lesser stages (Figs 3c \& 3d). 

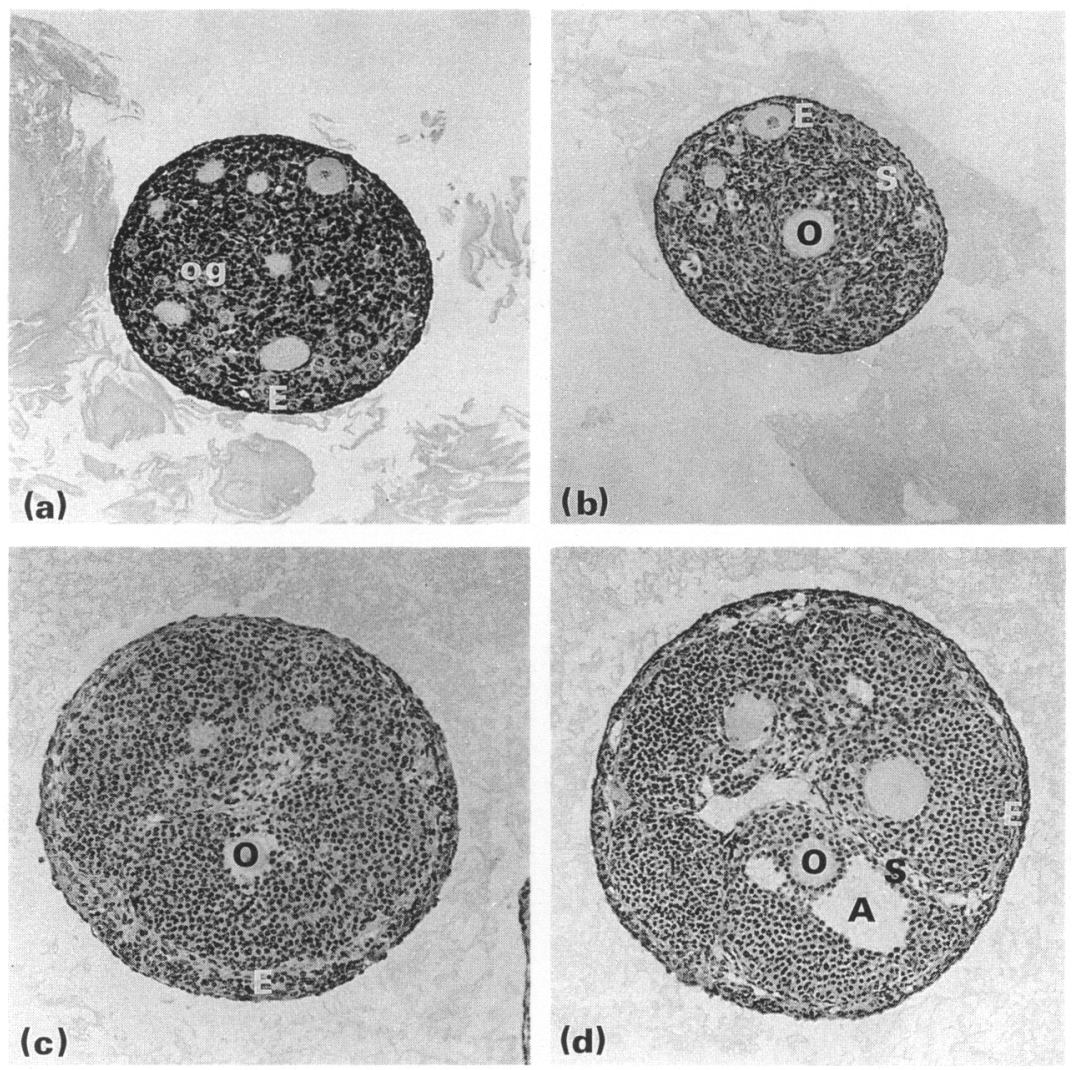

Fig. 3. Effect of the age of the mice on the stage of development reached in culture $(\times 90)$. $E=$ external cell layer; $\mathrm{O}=$ oocyte in most developed follicle. Primary follicles were obtained from ovaries of; (a) 5-day-old mouse, (b) 8 -day-old mouse ( $\mathrm{S}=$ partly differentiated layer of cortical stromal cells), (c) 12-day-old mouse and (d) 16-day-old mouse. $\mathrm{A}=$ antrum.

The concentrations of oestradiol in the spent culture medium paralleled the morphological findings (Fig. 4a). Oestradiol values were undetectable $(<0.03 \mathrm{~nm})$ in the cultures from the 5 - and 8-day-old mice, but for 12- and 16-day-old mice oestradiol concentrations increased with each change of the culture medium. For the 12-day-old mice the oestradiol concentration reached $13.5 \mathrm{~nm}$ after 11 days and then fell rapidly, indicating that atresia was occurring after this time. For the 16-day-old mice the oestradiol concentration continued to rise for 13 days and reached $22 \mathrm{~nm}$ (Fig. 4a).

\section{LH concentration}

Primary follicles from 14-16-day-old mice were cultured in 50\% children's serum containing only endogenous amounts of FSH and LH. They did not grow whatever the duration of the culture, but coalesced and reorganized into a characteristic spherical shape (Fig. 2a). The ova surrounded by 1 or 2 layers of proliferating cuboidal cells remained viable and the underlying cortical stroma was mildly proliferated. There was no evidence for any steroidogenesis by these follicles (see Fig. 4b for example). However, when the children's serum was supplemented with FSH (690 i.u./l) the primary follicles developed over 10 days, but at this level of LH (1.2i.u./l) the number of granulosa cell layers only increased to 3 or 4 (typical of Stage IV or V follicles).

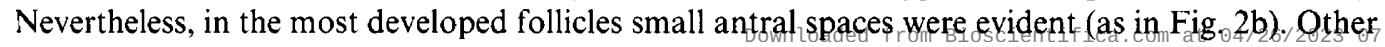



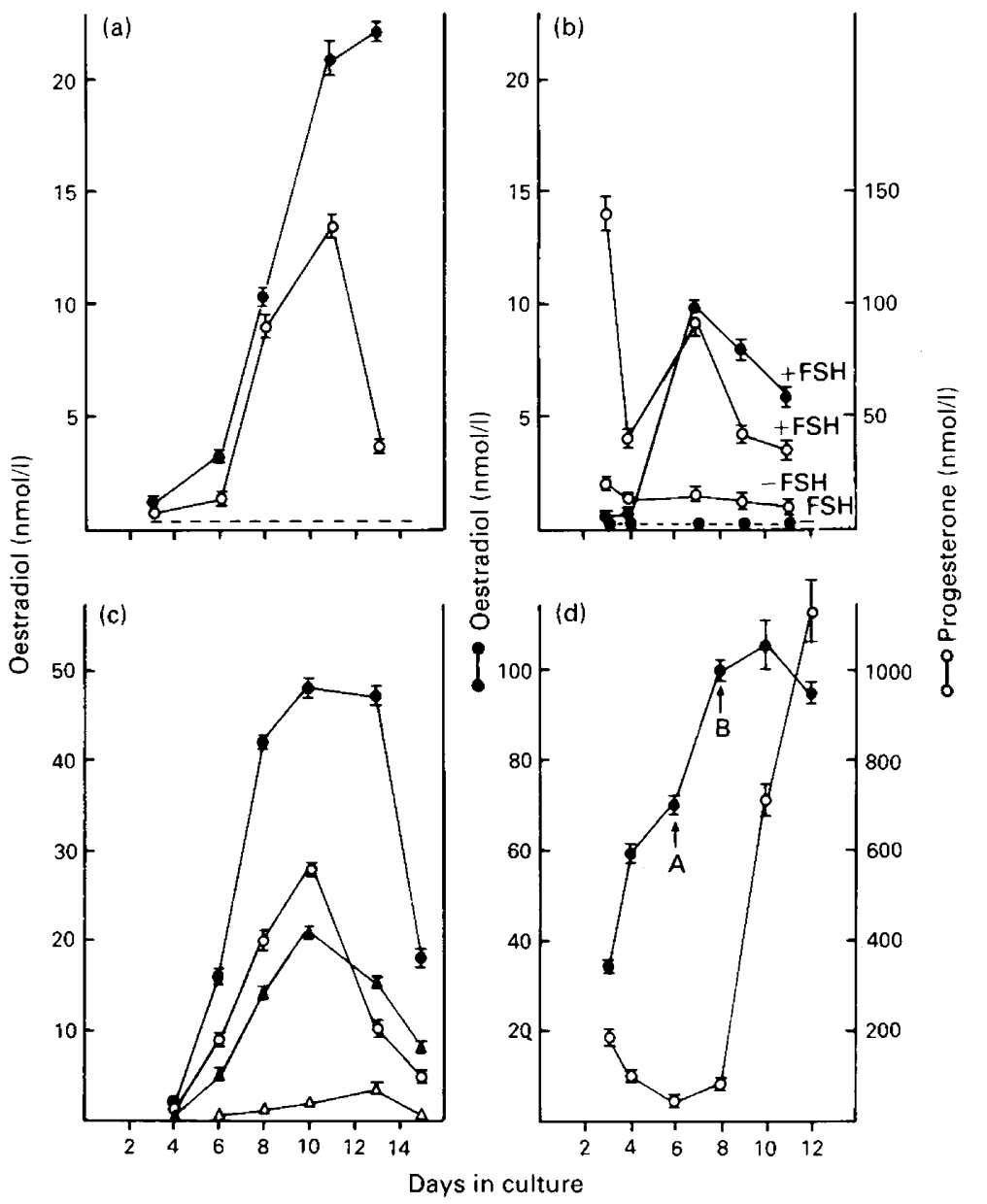

Fig. 4. Typical oestradiol and progesterone production profiles in the spent culture medium during in-vitro cultures. (a) Effect of age of mice: -- -, 5- and 8-day-old mice; 0,12 -day-old mice; 16-day-old mice. (b) Effect of in-vitro culture of primary follicle clusters in children's serum. (c) Effect of FSH concentration on steroid production: $\triangle, 86$ i.u. total $\mathrm{FSH} / \mathrm{l} ; \boldsymbol{\Delta}$, 239 i.u. total FSH/l; $\bigcirc, 464$ i.u. total FSH/1; - 690 i.u. total FSH/l. (d) Steroid production from in-vitro culture in Millicell plates. A: FSH concentration increased from 690 i.u./l to 1030 i.u./l; B: hCG (2 i.u./ml) added. Results are means \pm s.d.

follicles in the cluster developed to lesser stages. Small amounts of oestradiol were produced between Days 4 and 7 of culture (Fig. $4 \mathrm{~b}$ ) but thereafter the rate of production declined, indicating the onset of atresia. The progesterone concentration in the spent medium also increased between Days 4 and 7 but declined thereafter in parallel with the oestradiol concentration (Fig. 4b). It was concluded that the amount of $\mathrm{LH}$ contained in $50 \%$ post-menopausal serum was necessary to achieve sustained growth.

\section{FSH concentration}

The experiments described above were repeated using 50\% post-menopausal serum contributing 14 i.u. FSH/l and 19 i.u. LH/l (determined by RIA) supplemented with increasing concentrations of FSH (Preparation A) in the range 72-675 i.u./1 to give total FSH concentrations in the media ranging from 86 to $690 \mathrm{i} . \mathrm{u} . / \mathrm{l}$. The culture medium changes were analysed for oestradiol and the $_{41 \mathrm{AM}}$ 
follicles were fixed and sectioned after 15 days. The follicles are shown in Fig. 5 and the oestradiol responses are shown in Fig. 4(c). The primary follicles showed increasing stages of granulosa cell development and increasing oestradiol concentrations with increasing concentrations of FSH as follows: total FSH 86 i.u./l, Stage V (Fig. 5a), oestradiol reached $3 \mathrm{nmol} / 1$ (Fig. 4c): total FSH 239 i.u./l, Stage VI (Fig. 5b) with small antral spaces, oestradiol reached $21 \mathrm{nmol} / 1$ (Fig. 4c); total FSH 464 i.u./1, Stages VI-VII (Fig. 5c), oestradiol reached $28 \mathrm{nmol} / 1$ (Fig. 4c); total FSH 690 i.u./1, Stages VII-VIII (Fig. 5d), oestradiol reached $48 \mathrm{nmol} / 1$ (Fig. $4 \mathrm{c}$ ). The cluster resulting from culture of primary follicles in the presence of $464 \mathrm{i}$.u. FSH/1 is pictured in Fig. $5(\mathrm{c})$ which shows proliferated cortical stroma and parts of other proliferated follicles. The ova were healthy but meiosis had not recommenced. The ova in the most developed follicles grown in the presence of $690 \mathrm{i} . \mathrm{u}$. FSH/1 (as shown in Fig. 5d) were also viable but in a state of arrested meiosis. In all cases, the oestradiol concentrations began to fall after 10 days, indicating that some follicles were becoming atretic. Histological evidence for atresia was seen in some of the sections neighbouring the one with the largest follicle. This effect was more delayed with the highest dose of FSH (Fig. 4c).
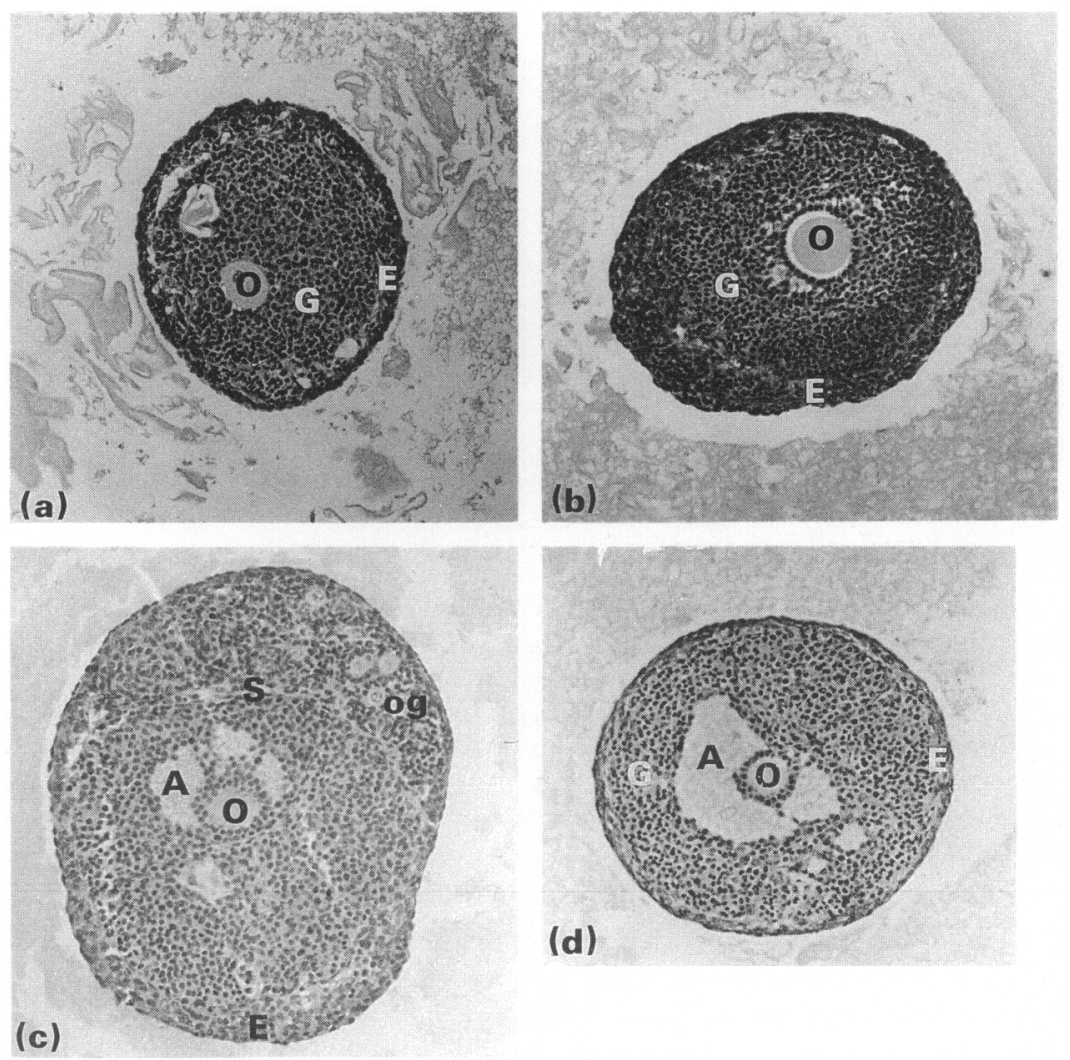

Fig. 5. Examples of follicles $(\times 110)$ grown in culture for 15 days with various concentrations of FSH: (a) 86 i.u./l; (b) 239 i.u./l; (c) 464 i.u./l; (d) 690 i.u./l. O = oocyte in most developed follicle; $\mathrm{A}=$ antrum; $\mathrm{S}=$ stromal cell layer; $\mathrm{E}=$ external cell layer.

\section{Optimum culture conditions and growth of preovulatory follicles}

From the above experiments the optimum culture conditions were chosen as follows. The primary follicles were placed in Petriperm culture dishes containing sufficient post-menopausal 

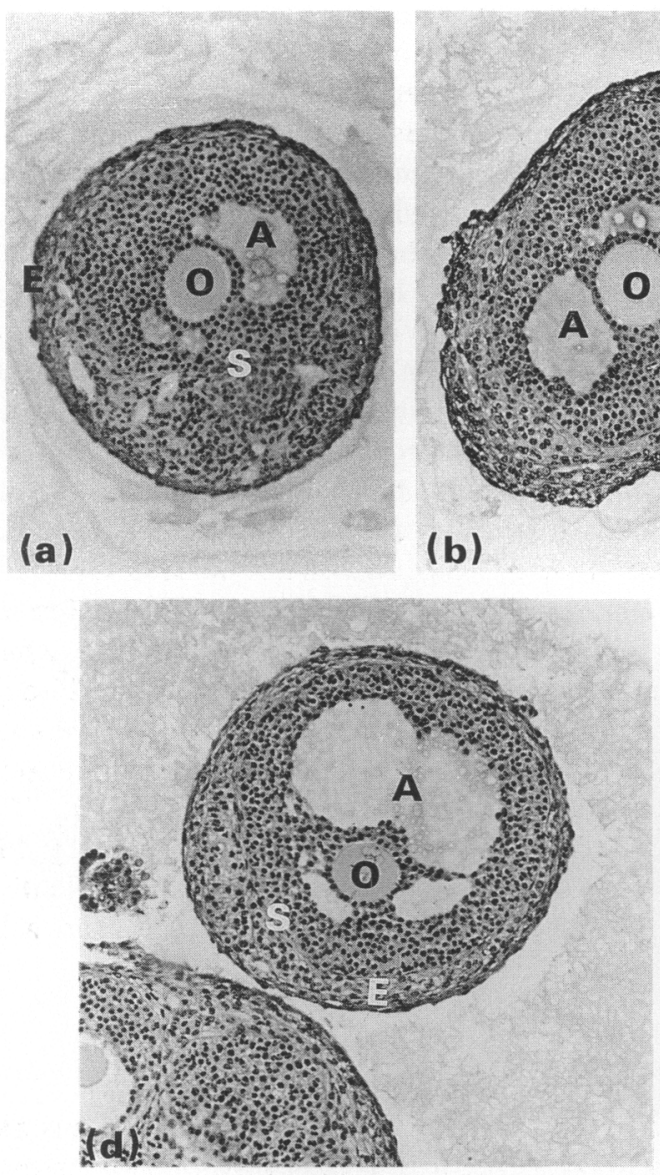

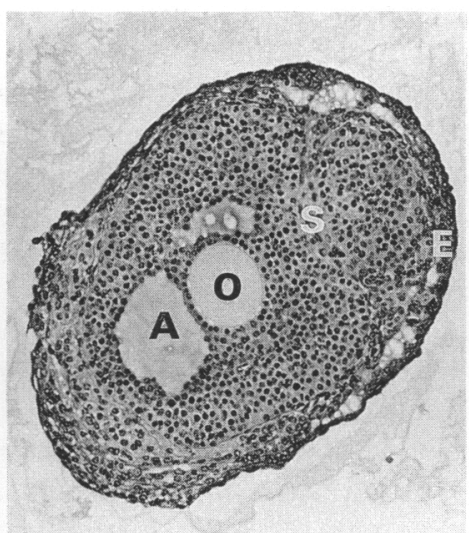

(b)
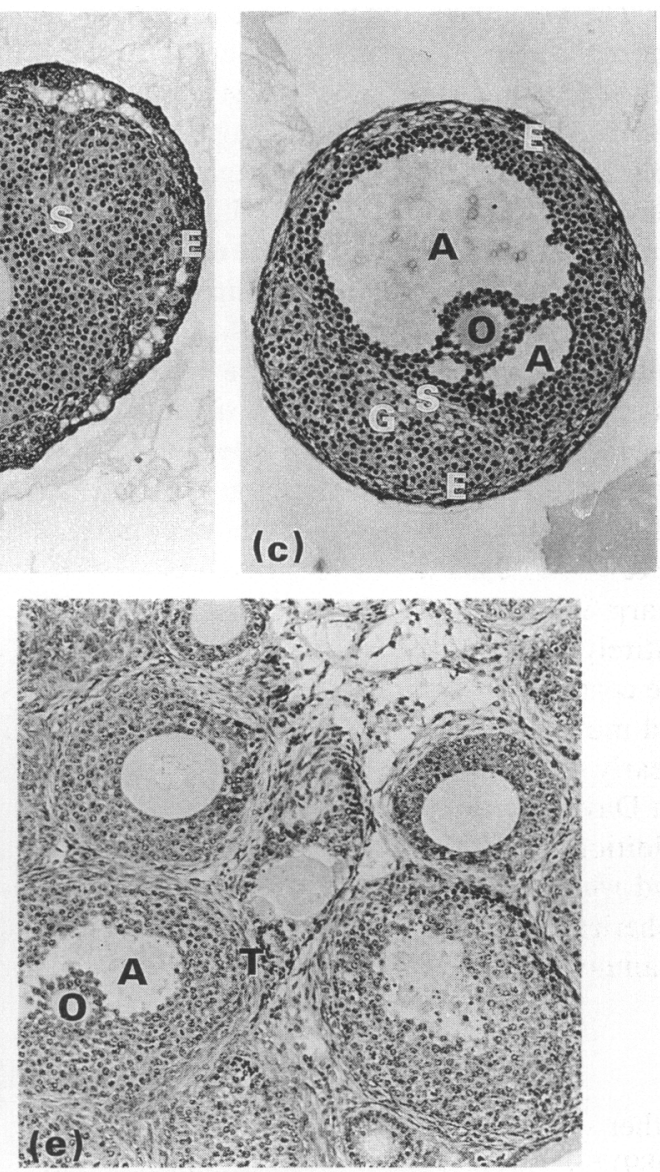

Fig. 6. Examples of antral and preovulatory follicles grown in vitro from primary follicles. (a \& b) Two examples $(\times 110)$ of response of cultures to FSH $(690$ i.u. $/ 1)$ in Millicell plates. $\mathrm{O}=$ oocyte in the most developed follicle; $\mathrm{A}=$ antrum; $\mathrm{S}=$ stromal cell layer; $\mathrm{E}=$ external cell layer. (c \& d) Examples of Graafian follicles $(\times 110)$ grown from different primary follicles in culture. Note the section of a second cluster in (d). $O=$ oocyte; $A=$ antrum; $G=$ granulosa cells; $\mathrm{S}=$ stromal cell layer; $\mathrm{E}=$ external cell layer. (e) An ovarian slice obtained from a 20-day-old mouse for comparison with the cultured follicles. $\mathrm{O}=$ oocyte; $\mathrm{A}=$ antrum; $\mathrm{T}=$ thecal layer.

serum $(50 \%)$ diluted with medium to just cover them. The total FSH concentration was 690 i.u./l. To obtain constant conditions, the dishes were placed in a vessel which was contained in an incubator at $37^{\circ} \mathrm{C}$ with a controlled atmosphere of $\mathrm{CO}_{2}$. The vessel was continually gassed with a mixture of $\mathrm{CO}_{2}(5 \%)$ in air saturated with water vapour. Under these conditions the $\mathrm{pH}$ was maintained at $7 \cdot 4$. The follicles were examined under the dissecting microscope every 2 days until either an antrum was clearly visible or the maximum period of culture was attained. The experiment was then terminated and all the follicle clusters which had formed were taken for sectioning. Under these culture conditions an antral follicle (similar to Figs $3 \mathrm{~d} \& 5 \mathrm{~d}$ ) was obtained in $83 \%$ of the experiments $(5 / 6)$ and all follicles incorporated in the cluster had grown beyond the primary stage. In the sixth case, 3-4 layers of granulosa cells had grown in the most developed follicle but no antrum was visible. 
The above experiments were repeated using Millicell culture plates which also have a hydrophobic membrane but only require $0.5 \mathrm{ml}$ culture medium. In 24 of 27 separate experiments an antral follicle (Stages VI-VII) developed in 6-7 days compared with 10-12 days using Petriperm plates. The sizes of the antra and the number of granulosa cell layers (usually 3-10 layers) presumably reflected different rates of growth of the primary follicles. Usually only one of the primary follicles developed to the antral stage in each cluster but all follicles increased their number of granulosa cell layers. Examples of the stage of development reached by the follicles in different experiments are shown in Figs 6(a) \& 6(b).

Development of follicles to the preovulatory stage was achieved by culture in Millicell plates as follows. On the 6th day of culture the FSH concentration was increased to 1030 i.u./l and on the 8th day human chorionic gonadotrophin (hCG, 2 i.u. $/ \mathrm{ml}$ ) was added to simulate the early preovulatory rise in LH. Oestradiol and progesterone were measured in the changes of medium and the experiment was terminated on the 10th day. After the addition of hCG, full preovulatory follicles (Stages VII-VIII) were obtained in 5 out of 6 experiments with large antra and cumuli oophori (as in Figs $6 c \& 6 d)$. The granulosa cells were well preserved but the ova had not resumed meiosis. There was a sharp line of demarcation by a fine membranous structure between the follicle (apparently formed entirely of granulosa cells) and the surrounding stimulated and proliferated but completely separate cortical stromal cells. For comparison a natural preovulatory follicle obtained from a 20-dayold mouse is shown (Fig. 6e); in this follicle the surrounding well differentiated thecal layers are clearly evident. The production of oestradiol increased throughout the culture period with a spurt on Day 6 due to the addition of the extra FSH and reached $100 \mathrm{nmol} / 1$ by Day 10 (Fig. $4 \mathrm{~d}$ ). The addition of hCG on Day 8 caused a dramatic increase in the production of progesterone (Fig. 4d), and when viewed under the dissecting microscope oocytes were seen extruding from the floating spherical clusters into the culture medium. Some of these extruded oocytes were surrounded by granulosa cells.

\section{Discussion}

Other workers have attempted culture of ovarian follicles (Ryle, 1969, 1971; Roy \& Greenwald, 1989) but this is the first time that primary ovarian follicles have been grown in vitro to the preovulatory stage. In developing this system, emphasis was placed on reproducing the conditions known to occur in mice (Peters, 1969; Ryle, 1969, 1971; Pedersen, 1970; Peters \& McNatty, 1980). The evidence that growth of preovulatory follicles has been achieved is based on morphological and biochemical (steroidogenic) criteria. The problem with the morphological criteria is that they involve destruction of the follicle. It could therefore be argued that an advanced follicle was included unwittingly in the original material cultured. This could then appear in the final product as the largest follicle sectioned which was the one on which success of the culture system was judged. Furthermore, several pieces of ovarian tissue containing primary follicles were cultured in each experiment to ensure that sufficient material was available for study and this could increase the chances of including a larger follicle. However, such contamination is very unlikely for the following reasons.

(a) The pieces of ovarian tissue were small and were carefully chosen under the dissecting microscope so that all follicles larger than Stage III were excluded (as in Fig. 1). The enlargement of the follicles in the spherical clusters which formed during the first $48 \mathrm{~h}$ of culture could be clearly seen particularly after the formation of antra. It is therefore practically impossible to overlook a larger follicle in such small pieces of tissue.

(b) Control experiments using unsupplemented children's serum showed only unchanged primary follicles (see Fig. 2a).

(c) The serial measurement of oestradiol and progesterone in the culture medium provided a non-destructive method for monitoring follicular growtheacthe smalb follicles which developed in : 04:41AM 
the children's serum (Fig. 2b) in the presence of exogenous FSH produced about 8 pmol oestradiol/ day. This value can be taken as a minimum measure of the steroid output of a Stage IV-V mouse follicle. McNatty (1981) has shown that the granulosa cells from healthy human preantral follicles respond to FSH with a marked stimulation (5-fold) of oestradiol production in in-vitro culture. Therefore, if undetected Stage IV (or greater) follicles were in fact present, the oestradiol production between Days 0 and 2 of culture in Petriperm dishes $(2.5 \mathrm{ml}$ volume $)$ should already be about 6-7 nM or greater, but lags in oestradiol production were actually observed at this time (oestradiol $<1 \mathrm{nM}$ ).

(d) The hormone measurements always paralleled the histological assessment of growth in culture.

(e) Although the stage of growth was defined by the largest follicle seen in section this was not an isolated observation since other follicles in that culture reached similar sizes. A notable feature of the results was that primary follicles from different animals obtained over a period of months and cultured under the same conditions responded consistently. The most developed follicles from each culture were always at a similar stage of development (Figs 3d \& 5d, and 6a \& 6b, for example) in all of the experiments under the same conditions. The same situation prevailed for other levels of FSH. Follicles which had developed to a lesser extent were also seen.

(f) After culture, the coalesced follicles showed a characteristic spherical shape surrounded by a well defined layer of cells presumably reflecting the ability of the normal ovary to regenerate itself after the tissue damage caused by ovulation. This could be clearly distinguished histologically from a section through a normal ovary (see Fig. 6e).

(g) The organization of the theca surrounding the follicles in a normal mouse ovary (Fig. 6e) is quite distinct from that seen in the follicles grown in culture (Figs. 6c \& 6d).

When all other conditions were kept constant, the age of the mice from which the primary follicles were obtained was an important determinant of follicle growth. The lack of growth of primary follicles obtained from 4-8-day-old mice could be a gonadotrophic effect. Stiff et al. (1974) and Dullaart et al. (1975) measured circulating FSH concentrations in mice as a function of age and found that, after birth, FSH values rose to a peak on about Day 10 and then declined rapidly. This peak is approximately 10 times that seen in adult mice and its function is probably to prime the follicles for later response to rises in FSH (Eshkol et al., 1971; Baker \& Scrimgeour, 1980). The present system would provide an excellent model for testing this hypothesis.

The concentration of FSH used here for full preovulatory development may seem to be excessively high. However, Ryle (1971) required similar levels to produce antral spaces in culture of whole ovaries. Also, 1 i.u. of human FSH is approximately the dose required to stimulate uterine growth in immature mice (the mouse uterus test), i.e. to induce oestradiol output sufficient to cause uterine growth. As the total volume of serum in a mouse is $2 \mathrm{ml}$ (Green, 1966), this represents a circulating level of $500 \mathrm{i} . \mathrm{u} . / 1$ which is close to the level used here. FSH was effective in producing large antral follicles (Stage VI or greater) only when adequate amounts of LH were present. When the endogenous levels of $\mathrm{LH}$ were $<8$ i.u./l, the follicles remained small although antral spaces were evident (Fig. 2b), and the peak oestradiol production rate was about $1 / 5$ of that obtained using the higher levels contained in post-menopausal serum (compare Figs $4 \mathrm{~b} \& 4 \mathrm{c}$ ). The amount of LH being supplied to the culture from the post-menopausal serum (20i.u./l) was equivalent to about $2 \mathrm{ng} /$ culture well, assuming a specific activity of $5 \mathrm{i.u} . / \mu \mathrm{g}$. This is lower than the levels circulating (about $36 \mathrm{ng} / 2 \mathrm{ml}$; Dullaart et al., 1975) in the serum of mice in vivo but was clearly sufficient to promote full antral development without supplementation.

The most important conclusion arising from this study is that growth of primary follicles in culture depends on the presence of adequate concentrations of FSH. No growth of primary follicles was seen unless sufficient FSH was present and, when requirements for growth factors and $\mathrm{LH}$ were met by including $50 \%$ post-menopausal serum, each stage of development achieved was related to a specific dose of FSH. More developed stages were not attained unless the dose was increased to an appropriate level, irrespective of the duration of the 6 ulture. In agreement with the findings from $\mathrm{m}_{41 \mathrm{AM}}$ 
histology the rate of oestradiol production also increased in a dose-dependent manner (Fig. 4c). In Petriperm culture dishes, atresia of at least some of the follicles, as evidenced by falling oestradiol values, consistently set in after 10-14 days in culture. Full development of antral or preovulatory follicles was therefore dependent on a concentration of FSH sufficient to stimulate growth within $8-10$ days ( $>690$ i.u./l). It was necessary to maintain this level throughout the culture period; if it was reduced around Day 7 the oestradiol concentrations declined immediately.

The more rapid rate of growth of the follicles achieved at all FSH levels in Millicell culture plates was probably related to the higher concentration of oestradiol which accumulated in the smaller volume of culture medium but this was not tested. Even in these plates, to achieve preovulatory follicles consistently within 8-10 days, it was necessary to increase the concentration of FSH to 1030 i.u./ 1 and to add hCG after 8 days. These times for production of preovulatory follicles are shorter than the estimate of 12-19 days given by Pedersen (1970) for the transformation of a Stage III follicle into a Stage VII-VIII follicle.

As a follicle matures in to a preovulatory structure its granulosa cells transform from an oestrogensecreting tissue into a progesterone-secreting one (McNatty \& Sawers, 1975; McNatty et al., 1979). The ability of the granulosa cells to make this transformation at ovulation appears to depend on their ability to respond to LH (McNatty, 1981). The response of the follicles by markedly increasing the rate of progesterone production after the addition of hCG (Fig. 4d) therefore indicates that the granulosa cells have indeed acquired the necessary LH receptors and are responding normally. In the cultured follicles, there was proliferation of the cortical stromal cells but their orientation was not completely indicative of thecal differentiation (Figs $6 \mathrm{c} \& 6 \mathrm{~d}$ ). Despite this incomplete thecal differentiation the oestradiol and progesterone profiles associated with the follicle growth (Fig. 4d) were entirely consistent with the patterns generally found in mammals. The cortical stromal cells must therefore be functioning to provide the necessary steroidal precursors for oestradiol production since immunohistochemical experiments show that cholesterol sidechain-cleavage and 17 $\alpha$-hydroxylase cytochrome P-450 enzymes (Sasano et al., 1989) are localized in theca interna cells and not in the granulosa, confirming the 2-cell theory (McNatty et al., 1979; Hillier, 1981; Lipsett, 1986). Organized proliferation and steroidogenesis of the granulosa cells in culture (as clearly seen in Figs $6 \mathrm{c} \& 6 \mathrm{~d}$ ) obviously does not require the presence of a fully differentiated and vascularized thecal layer.

Even in the most advanced follicles produced, the oocytes, although still healthy, had not resumed meiosis. This is probably due to the fact that the culture conditions are not yet optimized for the final maturation and ovulation of the oocyte. In this work the earliest stages of maturation up to the beginning of development of the antrum were easily and reproducibly achieved (Figs 3d \& 5d; 6a \& 6b). The later stages have proved to be more critical with regard to culture conditions and it is not surprising that changes need to be made at this stage. Furthermore, as the follicles increase in size they are likely to be more dependent on oxygen concentrations and other factors such as ascorbic acid supplies to regenerate essential cofactors. We expect that further refinement of this culture system will provide the conditions required to mature the oocytes so that they can be ovulated and fertilized to yield living offspring by embryo transfer which is the final proof of normality. This culture model has many applications; for example, it will allow experimental testing of the threshold hypothesis (Brown, 1978) and of the view that FSH is essential for the growth of primary follicles as indicated by this study rather than that development of primordial and primary follicles is independent of gonadotrophins (Gougeon, 1986).

We thank Dr Meg Smith and Dr Penny Nayudu for discussions and advice; Dr C. S. Lee, Dr J. Osborne and Dr A. Trounson for expert assessment of the follicles; the Histology Department of the Royal Women's Hospital; and Dr A. Tait Smith for his detailed histological assessment of the large number of sections produced during this work. This work was supported by grants from $\mathrm{NH}$ \& MRC and a research grant from the Royal Women's Hospital. 


\section{References}

Baker, T.G. \& Scrimgeour, J.B. (1980) Development of the gonad in normal and anencephalic human fetuses. J. Reprod. Fert. 60, 193-199.

Brown, J.B. (1978) Pituitary control of ovarian function concepts derived from gonadotrophin therapy. Aust. N.Z. J. Obstet. Gynaecol. 18, 47-54.

Brossemer, R.W. \& Rutter, W.J. (1961) The effect of oxygen tension on the growth and metabolism of mammalian cells. Expl Cell Res. 25, 101-113.

Dullaart, J., Kent, J. \& Ryle, M. (1975) Serum gonadotrophin concentrations in fertile female mice. $J$. Reprod. Fert. 43, 189-192.

Eshkol, A., Lunenfield, B. \& Peters, H. (1971) Ovarian development in infant mice. In Gonadotrophins and Ovarian Development, pp. 249-258. Eds W. R. Butt, A. C. Crooke \& M. Ryle. Churchill Livingstone, Edinburgh.

Gougeon, A. (1986) Dynamics of follicular growth in the human: a model from preliminary results. Human Reprod. 1, 8I-87.

Green, E.L. (1966) Biology of the Laboratory Mouse, p. 340. McGraw-Hill, London.

Hillier, S.G. (1981) Regulation of follicular oestrogen biosynthesis: a survey of current concepts. J. Endocr. 89, 3-18.

Lipsett, M.B. (1986) Steroid hormones. In Reproductive Endocrinology, pp. 140-153. Eds S. S. C. Yen \& R. B. Jaffe. W.B. Saunders, Philadelphia.

Mandl, A.M. \& Zuckermann, S. (1951) Numbers of normal and atretic oocytes in unilaterally spayed rats. J. Endocr. 7, 112-119.

McNatty, K.P. (1979) Ovarian follicular development from the onset of luteal regression in humans and sheep. In Follicular Maturation and Ovulation, pp. 1-18. Eds R. Rolland, E. V. van Hall, S. G. Hillier, K. P. McNatty \& J. Schoemaker. Excerpta Medica, Amsterdam.

MeNatty, K.P. (1981) Hormonal correlates of follicular development in the human ovary. Aust. J. biol. Sci. 34, 249-268.

MeNatty, K.P. \& Sawers, R.S. (1975) Relationship between the endocrine environment within the Graafian follicle and the subsequent rate of progesterone secretion by human granulosa cells in vitro. J. Endocr. 66, 39l-400.

MeNatty, K.P., Makris, A., De Grazia, C., Osathanondh, R. \& Ryan, K.J. (1979) The production of progesterone, androgens and oestrogens by human granulosa cells, thecal tissue and stromal tissue in-vitro. J. clin. Endocr. Metab. 49, 687-699.
Neal, P. \& Baker, T.G. (1975) Response of mouse Graafian follicles in organ culture to varying doses of follicle stimulating hormone and luteinizing hormone. J. Endocr. 65, 27-32.

New, D.A.T., Coppola, P.T. \& Terry, S. (1973) Culture of explanted rat embryos in rotating tubes. $J$. Reprod. Fert. 35, 135-138.

Pedersen, T. (1970) Follicle kinetics in the ovary of the cyclic mouse. Acta endocr., Copenh. 64, 304-326.

Pedersen, T. \& Peters, H. (1968) Proposal for a classification of oocytes and follicles in the mouse ovary. $J$. Reprod. Fert. 17, 555-557.

Peters, H. (1969) The development of the mouse ovary from birth to maturity. Acta endocr., Copenh. 62, 98-116.

Peters, H. \& McNatty, K.P. (1980) The development of the ovary from birth to maturity. In The Ovary, a Correlation of Structure and Function in Mammals, pp. 106-112. Eds H. Peters \& K. P. MeNatty. University of California Press, Berkeley.

Roy, S.K. \& Greenwald, G.S. (1985) An enzymatic method for dissociation of intact follicles from the hamster ovary. Histological and quantitative aspects. Biol. Reprod. 32, 203-215.

Roy, S.K. \& Greenwald, G.S. (1989) Hormonal requirements for the growth and differentiation of hamster pre-antral follicles in long term cultures. $J$. Reprod. Fert. 87, 103-[14.

Ryle, M. (1969) A quantitative in-vitro response to follicle stimulating hormone. J. Reprod. Fert. 19, 87-94.

Ryle, M. (1971) The time factor in responses to pituitary gonadotrophins by mouse ovaries in vitro. J. Reprod. Fert. 25, 61-74.

Sasano, H., Okamoto, M., Mason, J.I., Simpson, E.R., Mendelson, C.R., Sasano, N. \& Silverberg, S.G. (1989) Immunolocalisation of aromatase, $17 \alpha$-hydroxylase and side-chain-cleavage cytochromes P-450 in the human ovary. J. Reprod. Fert. 85, 163-169.

Soleto, J.R. \& Brauer, M. (1975) Removal of intact follicles from immature mouse ovaries. Differentiation 4, $81-84$.

Stifi, M.E., Bronson, F.H. \& Stentson, M.H. (1974) Plasma gonadotrophin in prenatal and prepubertal female mice: disorganization of pubertal cycles in the absence of a male. Endocrinology 94, 492-496.

Received 16 August 1989 